\title{
Measurement of Blood Loss by Means of a Whole-body Counter
}

\author{
J. M. HOLT,* M.D., M.R.C.P. ; F. G. H. MAYET,*† M.D. ; G. T. WARNER*; \\ S. T. CALLENDER,* M.D., F.R.C.P.
}

Brit. med. F., 1967, 4, 86-88

In the investigation of patients with hypochromic anaemia the assessment of the part played by gastrointestinal or menstrual blood loss is often extremely difficult. This paper describes a method for the measurement of blood loss over periods of up to three months by means of ${ }^{59} \mathrm{Fe}$ and the simple whole-body counter recently designed in this department (Callender et al., 1966). The principles involved are that 7 to 10 days after the administration of ${ }^{59} \mathrm{Fe}$ all or most of the dose will be incorporated into circulating red cells. In normal males and postmenopausal females the whole-body radioactivity will remain stable and any loss in total body radioactivity must represent loss of blood. The technique was evaluated by studying patients with polycythaemia from whom known quantities of blood were removed by venesection. Its clinical use is illustrated by studies of five patients with hypochromic anaemia.

\section{Methods}

The design of the whole-body counter and its uses in measuring absorption have been described in detail elsewhere (Warner and Oliver, 1966; Callender et al., 1966). The majority of subjects studied were given an intravenous tracer dose of ${ }^{59} \mathrm{Fe}$ ferric citrate with 1.5 to $1.0 \mu \mathrm{Ci}$ activity; subjects in whom additional information on the ability to absorb iron was required were given an oral dose of $5 \mathrm{mg}$. of ferrous iron labelled with approximately $5 \mu \mathrm{Ci}{ }^{59} \mathrm{Fe}$.

Patients Studied.-Four patients who had recovered from a myocardial infarct agreed to act as control subjects. All were outpatients and none was receiving anticoagulant drugs. They were studied over a period of three months in order to measure the normal daily iron loss as blood and to assess the week-toweek variation of the whole-body counter. Twelve patients with polycythaemia who required therapeutic venesection were studied; three were postmenopausal females and nine were males. Ten had polycythaemia vera and two had secondary polycythaemia. Plasma iron disappearance curves were plotted and used for estimation of blood volume. Seven to 10 days after the injection of ${ }^{59} \mathrm{Fe}$ (day zero of the experiment) the whole-body radioactivity was measured. Thereafter venesections were carried out at varying intervals of a few hours to three weeks. The whole-body radioactivity was measured immediately before and after each venesection. Five patients with iron-deficiency anaemia in whom either gastrointestinal bleeding or excessive menstrual loss was suspected were investigated. The proportion of the oral dose retained at 10 days was a measure of iron absorption. Thereafter the total body activity was measured at intervals.

Calculation of Blood Loss. $-\mathrm{L}=$ Percentage loss of wholebody radioactivity between counts. $\mathrm{BV}=\mathrm{Blood}$ volume in $\mathrm{ml}$.

$$
\text { Blood loss in } \mathrm{ml}=\frac{\mathrm{L}}{100} \times \mathrm{BV}
$$

In control subjects and patients with iron-deficiency anaemia the blood volume was taken to be $65.6 \mathrm{ml}$. $/ \mathrm{kg}$. body weight (Wasserman et al., 1951). For the purpose of this calculation it was thought reasonable to assume that in polycythaemia and

- Nuffield Department of Clinical Medicine, Radcliffe Infirmary, Oxford. t Present address: Department of Medicine, University of Natal, Durban. iron-deficiency anaemia the red-cell utilization of ${ }^{59} \mathrm{Fe}$ could be taken as $100 \%$. This was verified in a number of subjects. When $100 \%$ utilization was not expected-for example, in control subjects-the utilization was measured and the appropriate correction made.

\section{Results}

\section{Control Subjects}

The whole-body counts expressed as a percentage of the count on day zero were plotted against time in days (Fig. 1). The mean loss of ${ }^{59} \mathrm{Fe}$ per day was $0.031 \% \pm 0.039 \%$. The calculated blood loss per 100 days was $152,155,160$, and 182 $\mathrm{ml}$. respectively. After correction for the amount of blood removed for blood sampling the losses were $142,105,90$, and $132 \mathrm{ml}$. (mean $117 \mathrm{ml}$.).

\section{Patients with Polycythaemia}

A total of 39 venesections were carried out in the 12 patients, and the calculated volume of blood lost on each occasion was compared with the known volume of blood removed by venesection. The difference, or error, was expressed as a percentage of the known volume removed. In 10 instances between 100 and $300 \mathrm{ml}$. of blood was removed; the mean error was $-10 \%$, the range $-48 \%$ to $+63 \%$, and the standard deviation of the errors $\pm 36 \%$. On the other 29 occasions between 395 and $520 \mathrm{ml}$. of blood was removed; the mean error was $-12 \%$, the range $-60 \%$ to $+50 \%$, and the standard deviation of the errors $\pm 26 \%$.

\begin{tabular}{|c|c|c|c|c|}
\hline $\begin{array}{l}\text { Period of } \\
\text { Study in } \\
\text { Days }\end{array}$ & $\begin{array}{c}\text { Blood } \\
\text { Removed } \\
(\mathrm{ml} .)\end{array}$ & $\begin{array}{l}\text { Calculated } \\
\text { Blood } \\
\text { Loss (ml.) }\end{array}$ & $\begin{array}{l}\text { Difference } \\
(\mathrm{ml} .)\end{array}$ & $\begin{array}{c}\text { Error } \\
(\%)\end{array}$ \\
\hline $\begin{array}{r}1 \\
1 \\
2 \\
37 \\
40 \\
84 \\
90 \\
6 \\
97\end{array}$ & $\begin{array}{r}688 \\
715 \\
725 \\
1,190 \\
1,235 \\
1,630 \\
1,850 \\
2,025 \\
2,820\end{array}$ & $\begin{array}{r}586 \\
662 \\
825 \\
1,162 \\
968 \\
1,606 \\
2,280 \\
2,231 \\
2,761\end{array}$ & $\begin{array}{r}-102 \\
-53 \\
+100 \\
-28 \\
-267 \\
-24 \\
+430 \\
+206 \\
-59\end{array}$ & $\begin{array}{r}-15 \\
-7 \\
+14 \\
-2 \\
-22 \\
-1 \\
+23 \\
+10 \\
-2\end{array}$ \\
\hline
\end{tabular}

The Table concerns the nine patients in whom blood was removed by repeated venesection, carried out at intervals during periods of from 1 to 97 days. The sum of the calculated blood losses in each case is compared with the total volume removed by venesection. In these calculations only the whole-body count before each venesection was used in order to simulate the situation in which a patient with continuous blood loss was having single whole-body counts at intervals. The mean error was $-0.2 \%$, the range $-22 \%$ to $+23 \%$, and the standard deviation of the errors $\pm 14 \%$.

In order to demonstrate the relation between whole-body ${ }^{59} \mathrm{Fe}$ activity and blood loss the results from one patient are shown in Fig. 1, where the graph is compared with that from the control subjects. 


\section{Patients with Hypochromic Anaemia}

The results are shown in Figs. 2-6, where whole-body counts expressed as a percentage of the whole-body count on day zero are plotted against time in days. The percentage absorption of the orally administered dose and the blood loss are recorded.

One patient had occult gastrointestinal bleeding from telangiectases due to scleroderma, and Fig. 2 shows how most of the bleeding occurred during the first 21 days of the study. In 15 weeks 1.8 litres of blood was lost, but as she can absorb oral iron well her haemoglobin can be maintained at a satisfactory level by continuous treatment.

The second patient had recurrent iron-deficiency anaemia. Her iron absorption was normal and her anaemia was attributed to menorrhagia. The magnitude of the bleeding was not, however, fully appreciated until this study showed a loss of $870 \mathrm{ml}$. during a single menstrual period. Hysterectomy was therefore advised. Fig. 3 shows that the operation was performed without much loss of blood and that thereafter there was no significant fall in whole-body radioactivity, confirming that menorrhagia was the sole cause of her anaemia.

The third patient was an 18-year-old boy who complained of increasing shortness of breath and cough with haemoptysis. He was found to have a severe hypochromic anaemia, and a chest radiograph showed diffuse opacities in both low $=r$ lobes. Fig. 4 shows that the whole-body radioactivity remai.'.d con- stant despite a fall in haemoglobin, indicating that blood loss was not the cause of the anaemia. Later, iron-containing macrophages were found in the sputum and a diagnosis of idiopathic pulmonary haemosiderosis was made. Though blood was being lost from the circulation, it was being sequestered in the lung, thereby explaining why the whole-body radioactivity did not fall.

The fourth patient was a 16-year-old boy with the EhlersDanlos syndrome who had recurrent iron-deficiency anaemia. Fig. 5 shows that he lost 1.3 litres of blood in 92 days from the gastrointestinal tract, and though it was not practicable to measure absorption of iron he was able to maintain a satisfactory haemoglobin provided he took iron by mouth continuously.

The fifth patient was a 53-year-old man with ankylosing spondylitis who had had a recurrent iron-deficiency anaemia for 12 years. During the period of study (Fig. 6) he had been taking between 1 and $2 \mathrm{~g}$. of paracetamol a day to control pain, and it seems likely that the gastrointestinal blood loss, which amounted to 1.2 litres in 105 days, was related to treatment.

\section{Discussion}

The method described here is sensitive enough to detect blood loss of the order of 100 to $300 \mathrm{ml}$. but with only limited
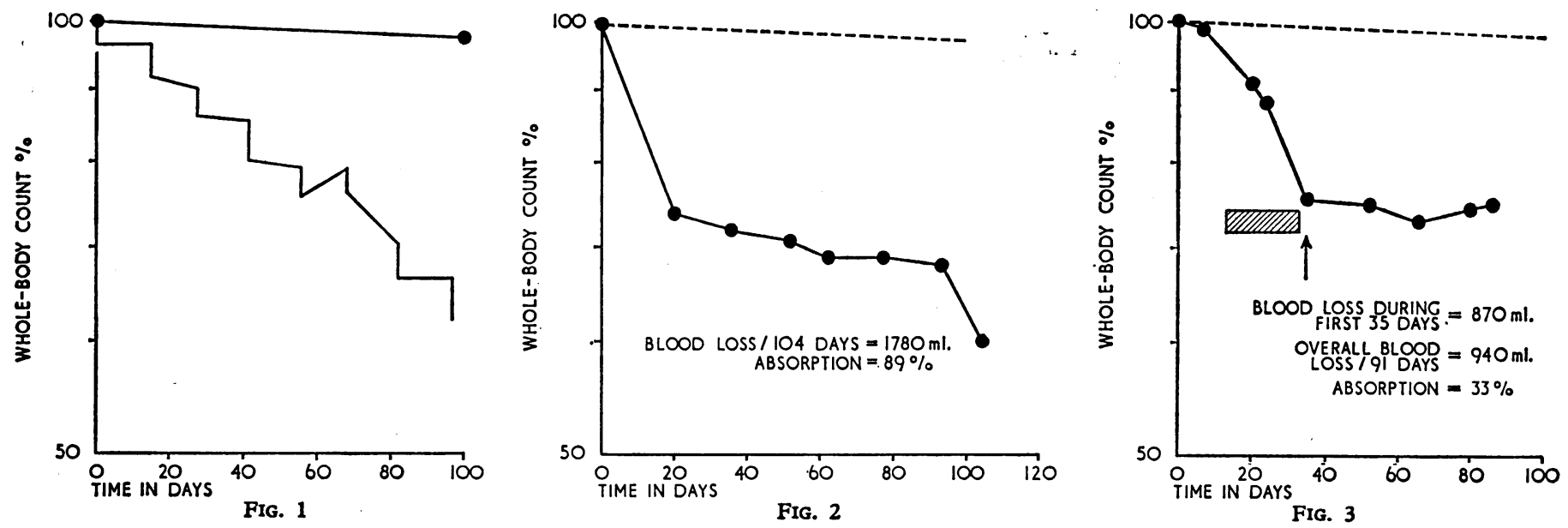

Fig. 1. Whole-body count expressed as percentage of the count on day zero plotted against time in days. $\longrightarrow$ Calculated graph from 4 normal subjects (mean ${ }^{84} \mathrm{Fe}$ loss per day, $0.031 \%+0.039 \%$ ). - Patient with polycy haemia. The steps correspond with venesections. The apparent rise in activity about day 60 is thought to be due to a combination of counting statistics and counter error. Fig. 2.-Wholebody counts in a patient with telangiectases and scleroderma. -.. Control graph. Fig. 3.- Whole-body counts in a patient with menorrhagia. The arrow indicates hysterectomy and the hatched area a menstrual period.
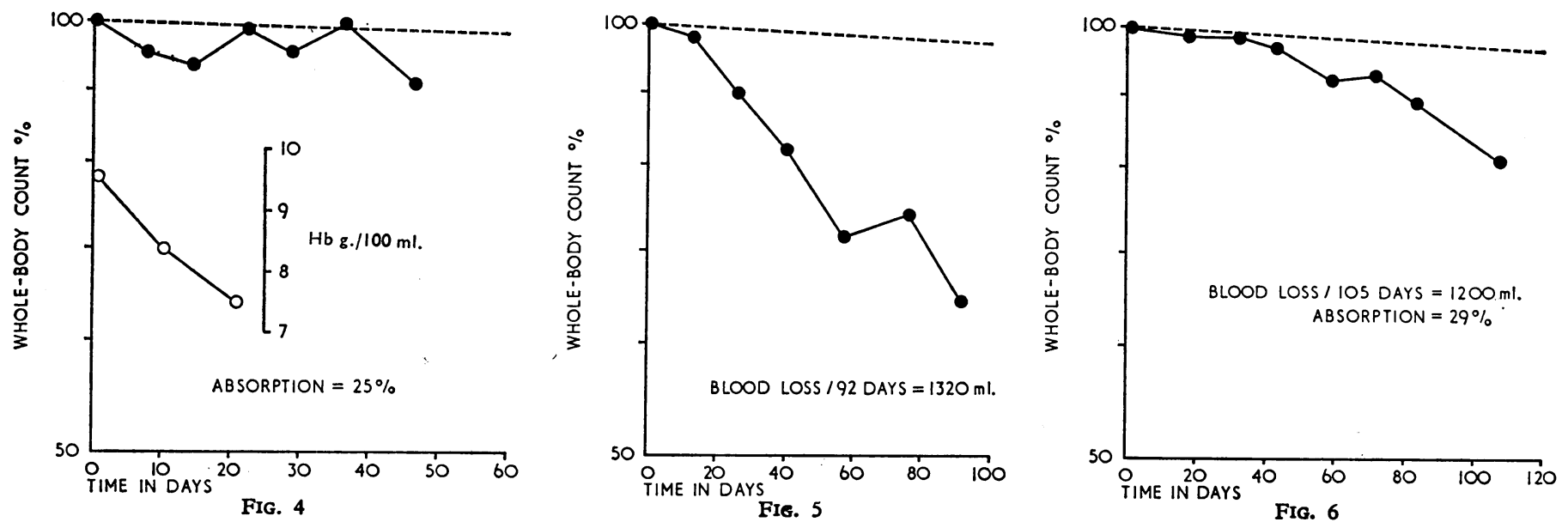

FIG. 4.-Whole-body counts in a patient with idiopathic pulmonary haemosiderosis. Despite a fall in haemoglobin the total body radioactivity remained constant, showing that the anaemia was not caused by blood loss. - . - . Control graph. Fig. 5. - Whole-body counts in a patient with the Ehlers-Danlos syndrome. -...- Control graph. FIG. 6. - Whole-body counts in a patient with ankylosing spondylitis who was taking paracetamol to control pain. ..... Control graph. 
accuracy and reproducibility (mean error $-10 \%$, standard deviation $\pm 36 \%$ ). Blood loss of the order of 400 to $500 \mathrm{ml}$. can be measured with greater reproducibility $(-12 \%, \pm 26 \%)$. However, blood loss of the order of 700 to $3,000 \mathrm{ml}$. computed from consecutive whole-body counts over periods of time ranging from 1 to 97 days can be measured with sufficient accuracy and reproducibility $(-0.2 \%, \pm 14 \%)$ to be of use in the quantitative assessment of blood loss in patients with hypochromic anaemia, over periods of up to three months.

Although a whole-body counter has previously been applied to clinical problems of blood loss (Price et al., 1964), the technique has never been evaluated critically. Price et al. calculated menstrual blood loss against a direct measurement of the ${ }^{59} \mathrm{~F}=$ - ontent of tampons in one case, and thought an error of $26-40 \mathrm{ml}$. in losses amounting to $33-59 \mathrm{ml}$. was likely. Nevertheless it is probably wrong to assume that blood loss occurring clinically can be measured with the same precision as was attained with venesection of patients with polycythaemia. Gastrointestinal or menstrual bleeding may occur erratically and lead to fluctuations in the red cell content of ${ }^{59} \mathrm{Fe}$ and blood volume, both of which cannot be corrected for.

By the above method we are unable to measure reliably blood loss of the order of $100 \mathrm{ml}$., and an accurate assessment of a single moderately heavy menstrual period is not possible. However, a more accurate measurement is possible if the patient is followed over three or four menstrual cycles.

The ease and simplicity of the technique described here is such that all the studies were carried out on subjects visiting the department as outpatients. The technique is now available in this hospital as a diagnostic service and is being used to study the mechanism of naemia in patients with hiatus hernia, ulcerative colitis, and Crohn's disease.

\section{Summary}

A method is described for the measurement of blood loss over periods of up to three months by means of ${ }^{59} \mathrm{Fe}$ and a whole-body counter. Patients with polycythaemia from whom known quantities of blood were removed by venesection were studied to evaluate this technique. The method is sensitive and accurate enough for clinical purposes, and blood loss of more than $700 \mathrm{ml}$. can be measured with reproducibility of $\pm 14 \%$. To illustrate its application to clinical problems, studies of five cases of hypochromic anaemia are described.

We wish to thank Miss Marjorie Alcock for technical assistance. The work was in part supported by a grant from the Medical Research Council.

REPERENCES

Callender, S. T., Witts, L. J., Warner, G. T., and Oliver, R. (1966). Brit. F. Haemat., 12, 276.

Price, D. C., Forsyth, E. M., Cohn, S. H., and Cronkite, E. P. (1964). Canad. med. Ass. 7., 90, 51.

Warner, G. T., and Oliver, R. (1966). Phys. in Med. Biol., 11, 83.

Wasserman, L., R., Tse-fei, Y., and Rashkoff, I. A. (1951). 7. Lab. clin. Med., 37, 342 .

\title{
Effect of Transfusion Materials on Rouleaux Formation and Sedimentation Rate of Erythrocytes
}

\author{
A. J. SALSBURY,* M.D.
}

Brit. med. F., 1967, 4, 88-90

The range and variety of plasma expanders and plasma substitutes are constantly increasing, particularly in the case of dextran solutions (Mollison, 1967 ; Brit. med. f., 1967). A relatively new dextran is dextran 110 , which has a high molecular weight though lower than that of the longer-established dextran 150. Ricketts (1966) has investigated the properties of a modified dextran similar to dextran 110 . He found that the effect of this dextran on the red-cell sedimentation rate was substantially less than that of dextran 150 and that red-cell aggregation in the rabbit was minimal. Rouleaux formation was found to interfere with cross-matching in only two out of nine patients who received modified dextran.

In view of these results, it was decided to undertake a series of investigations in vitro to determine the effect of dextran 110, dextran 150, Macrodex, a commercial plasma protein solution, and plasma itself upon red-cell rouleaux formation, blood typing, and cross-matching.

\section{Methods and Results}

In the experiments the following standard transfusion materials were compared: (1) reconstituted dried human plasma ; (2) a commercial $4.3 \%$ plasma protein solution (Serological Products Ltd.); (3) $6 \% \mathrm{w} / \mathrm{v}$ Macrodex in normal saline (Pharmacia (Great Britain) Ltd.) ; (4) $6 \% \mathrm{w} / \mathrm{v}$ dextran

\footnotetext{
- Department of Haematology, St. Bartholomew's Hospital, London E.C.1.
}

110 in normal saline (Fisons Pharmaceuticals Ltd.) ; (5) $6 \%$ $\mathrm{w} / \mathrm{v}$ dextran 150 in normal saline (Fisons Pharmaceuticals Ltd.). As a control, tests were also set up with normal saline in place of one of the above substances. All samples of blood were taken from healthy human volunteers into Sequestrene (sodium edetate). The Westergren sedimentation rate of each sample was $2 \mathrm{~mm}$. in the first hour. Three main sets of experiments were then performed.

Effect of Varying Concentrations of Transfusion Materials on the E.S.R.-The transfusion materials listed above were mixed with blood in dilutions of 1 in 10, 1 in 20, and 1 in 40 (Table I). Five different samples of blood were tested (Tests A-E). Citrate was added to each mixture and the samples were set up in Westergren tubes at room temperature, results being read at the end of one hour. The substitution of plasma or plasma protein solution for saline had no effect on the sedimentation rate (Table $I$ ). The substitution of dextran 150 markedly raised the E.S.R. The effect of dextran 110 was less pronounced, but still considerable, while that of Macrodex was moderate. The greater the concentration of Macrodex, dextran 110, or dextran 150, the greater their effect on the E.S.R. This increased effect, however, was much less pronounced with Macrodex than with dextran 110 or dextran 150 .

Effect of Transfusion Materials and Anaemia on the E.S.R. - The concentration of transfusion material added to blood was kept constant at 1 in 10 . Three different samples of blood were used (Tests I-III). The samples were adjusted by centrifugation and reconstitution of cells and plasma to give haemo- 